\title{
SISTEM PENJADWALAN IKLAN TERINTEGRASI PADA STASIUN RADIO SUARA KUDUS UNTUK PENINGKATAN EFEKTIVITAS DAN EFISIENSI PRODUKSI SIARAN
}

\author{
Noor Latifah \\ Fakultas Teknik, Program Studi Sistem Informasi \\ Universitas Muria Kudus \\ Email: noor.latifah@umk.ac.id \\ Putri Kurnia Handayani \\ Fakultas Teknik, Program Studi Sistem Informasi \\ Universitas Muria Kudus \\ Email: abdul.chamid@umk.ac.id \\ Syafiul Muzid \\ Fakultas Teknik, Program Studi Sistem Informasi \\ Universitas Muria Kudus \\ Email: syafiul.muzid@umk.ac.id \\ Yogi Andriawan \\ Fakultas Teknik, Program Studi Sistem Informasi \\ Universitas Muria Kudus
}

\begin{abstract}
ABSTRAK
Radio merupakan salah satu media layanan penyedia informasi bagi masyarakat. Informasi yang disampaikan kepada masyarakat bisa berupa iklan maupun berita. Radio Suara Kudus merupakan radio siaran milik pemerintah yang pengelolaan iklan belum menggunakan suatu sistem penjadwalan sehingga sering mengalami kendala dalam penjadwalan iklan dan waktu proses penjadwalan yang cukup lama dikarenakan tidak boleh terjadi tabrakan antar iklan, serta jadwal yang harus dipadatkan sedemikian mungkin agar dapat menampung banyak iklan dalam setiap siaran. Untuk mengatasi permasalahan tersebut, maka dikembangkan Sistem Penjadwalan Iklan Terintegrasi untuk membantu dalam pengelolaan jadwal iklan. Sistem dikembangkan menggunakan Java Netbeans dan database MySQL. Hasil penelitian adalah Sistem Penjadwalan Iklan Terintegrasi yang digunakan untuk mengelola iklan yang masuk sampai dengan iklan tersebut ditayangkan. Sistem ini memudahkan setiap bagian dalam berkoordinasi terkait penjadwalan iklan sehingga waktu dan proses yang dibutuhkan semakin cepat. Selain itu, penyiar juga dapat dengan mudah untuk melihat semua jadwal iklan dalam setiap siarannya serta dapat secara langsung memutarkan iklan tersebut tanpa mencari ke dalam file lain. Sehingga mampu meningkatkan efektivitas dan efisiensi produksi siaran serta kinerja khususnya untuk penjadwalan iklan.
\end{abstract}

Kata kunci: penjadwalan iklan, iklan radio, aplikasi penjadwalan.

\section{ABSTRACT}

Radio is one of the media service provider of information for the public. Information submitted to the community could be an ads or news. Radio Suara Kudus is a radio broadcast government-owned which doesn't have a scheduling system to manage ads. Radio Suara Kudus often has problems in ads scheduling and the time of scheduling process is too long. Because it should not happen collision between the ads, and the schedule should be compacted to accommodate a lot of ads in each broadcast. To overcome these problems, then developed the Integrated Ads Scheduling System to assist in managing the advertising schedule. The system was developed using Java Netbeans and MySQL database. In this research, The Integrated Ads Scheduling System is used to manage the ads untill broadcasted. This system facilitate any department used to coordinating good ads scheduling so that the time and process required more quickly. In addition, broadcasters can easily to see all the ads in each broadcast schedules and can directly play the ad without looking into computers files. So as to improve the effectiveness and efficiency of broadcast production and performance, especially for ads scheduling.

Keywords: ads scheduling, radio ads, scheduling system. 


\section{PENDAHULUAN}

Teknologi informasi dan komunikasi berkembang pesat salah satunya berpengaruh pada penyampaian informasi yang cepat melalui banyaknya media layanan penyedia informasi salah satunya yaitu melalui media radio. Radio merupakan salah satu media layanan penyedia informasi bagi masyarakat, informasi yang disampaikan kepada masyarakat bisa berupa iklan, berita, edukasi maupun hiburan. Pendapatan terbanyak dari radio diperoleh dari hasil penyiaran iklan produk atau jasa dikarenakan sering disiarkan secara berulang-berulang supaya informasi cepat diingat oleh masyarakat. Iklan merupakan salah satu cara untuk melakukan promosi baik barang maupun jasa. Iklan Radio adalah iklan yang dipasang melalui media radio. Iklan radio memiliki karakteristik yang khas yaitu hanya dapat didengar melalui audio (suara) yang merupakan perpaduan dari kata-kata (voice), musik dan sound effect [1]. Penyampaian iklan melalui radio dipilih dikarenakan salah satu media yang mudah dipahami oleh kebanyakan masyarakat.

Iklan dalam radio harus dikelola dengan baik sehingga diperlukan penjadwalan iklan yang tertata rapi. Penjadwalan (schedulling) adalah pengeturan waktu dari suatu operasi. Penjadwalan mencakup kegiatan mengalokasikan fasilitas, perlatan maupun tenaga kerja bagi suatu kegiatan operasi. Penjadwalan selalu berkaitan dengan pengalokasian sumber daya yang ada pada jangka waktu tertentu, hal tersebut adalah proses pengambilan keputusan yang tujuannya adalah untuk optimalisasi [2].

Stasiun Radio Suara Kudus, merupakan salah satu stasiun radio di Kabupaten Kudus yang di kelola oleh Sekda bagian Humas yang berlokasi di Jl. Jend. Sudirman 192 B (Komplek Ngasirah). Selama ini pengelolaan iklan di Radio Suara Kudus masih dilakukan secara manual termasuk untuk penjadwalan iklan sehingga membutuhkan waktu yang lama dikarenakan terjadinya bentrok antar jadwal iklan karena beberapa klien yang ingin meng-iklankan produk/jasanya meminta waktu tertentu dalam kurun waktu yang terbatas. Sehingga petugas pembuat jadwal iklan harus dengan secara extra membuat jadwal iklan yang baik serta mampu mengakomodasi semua keinginan dari klien. Rumitnya cara pembuatan jadwal penayangan iklan radio membuat pekerjaan penjadwalan iklan harus dikerjakan oleh petugas yang khusus dengan tingkat ketelitian yang tinggi [3]. Masalah juga dihadapi oleh bagian Marketing yaitu lamanya waktu ketika mencari slot jadwal yang masih kosong [4].

Selain itu, pada saat siaran petugas siar harus mencari iklan yang harus diputar didalam komputer, sehingga terkadang menyebabkan keterlambatan pemutaran atau durasi siaran menjadi molor diluar jadwal yang ditentukan. Serta belum adanya bukti siar iklan yang akan diberikan kepada klien terkait rekapitulasi iklan yang telah diputar sesuai dengan jadwal karena data-data tidak tersistem dan masih tergantung pada dokumen tertulis antar divisi yang rentan terhadap kesalahan data karena adanya faktor human error. Dan tentunya durasi dari iklan yang perlu disesuaikan dengan durasi program siaran agar bisa berjalan sesuai jadwal [5].

Untuk menjaga profesionalisme Radio Suara Kudus dalam mengelola penyiaran iklan serta penjadwalannya maka perlu dikembangkan sistem penjadwalan iklan yang terintegrasi untuk mempermudah kinerja antar bagian yang terlibat dalam pengelolaan iklan. Sistem Penjadwalan Iklan Terintegrasi yang dikembangkan dapat digunakan untuk mengelola iklan mulai dari proses order iklan, penjadwalan iklan sampai dengan penyiaran iklan yang terintegrasi serta pelaporan semua iklan yang telah disiarkan sesuai dengan keinginan pengiklan.

\section{METODOLOGI PENELITIAN}

\subsection{Metode Penelitian}

Metode yang digunakan dalam penelitian ini adalah metode prototype dan diawali dengan studi kepustakaan. Tahapan dari metode penelitian tersebut adalah sebagai berikut:

1) Studi pustaka

Studi pustaka dilakukan dengan cara mempelajari, mendalami, dan mengutip teori atau konsep dari sejumlah literatur, baik buku, jurnal yang relevan dengan topik penjadwalan terintegrasi, tinjauan pustaka, serta perkembangannya.

2) Pengembangan Sistem

Metode yang digunakan adalah metode prototype yaitu meliputi tahapan analisa, desain, pengkodean program, dan pengujian. Tahap analisa dilakukan untuk mengetahui fungsi-fungsi sistem yang akan dikembangkan berdasarkan analisa masalah serta siapa saja yang akan menggunakan sistem. Tahap desain digunakan untuk membuat rancangan desain alur sistem, proses yang ada didalam sistem, rancangan antarmuka dan rancangan database yang digunakan. Tahap pengkodean adalah proses pembuatan sistem menggunakan bahasa pemrograman Java Netbeans dan database MySQL. Tahap pengujian digunakan untuk menguji apakah sistem yang bangun telah berjalan sesuai fungsinya dan berjalan dengan sebagaimana mestinya. 


\subsection{Analisa Sistem}

Sistem Penjadwalan Iklan Terintegrasi pada Radio Suara Kudus adalah sistem informasi yang mengelola iklan pada radio yang meliputi proses:

1) Data order iklan dari klien dan data iklannya yang biasanya dalam bentuk mp3,

2) Jadwal acara siaran,

3) Jadwal iklan pada setiap acara siaran,

4) serta Proses penyiaran iklan tersebut.

Sistem Penjadwalan Iklan Terintegrasi digunakan oleh beberapa pengguna sebagai berikut:

1) Bagian marketing, yang bertugas menerima order iklan dari klien.

2) Bagian programmer siaran, yang bertugas untuk mengelola acara siaran dan menjadwalkan iklan pada acara siaran yang ada.

3) Bagian penyiar, bertugas untuk memutar iklan yang sudah dijadwalkan pada acara.

\subsection{Perancangan Sistem}

Perancangan sistem pada Sistem Penjadwalan Iklan Terintegrasi Radio Suara Kudus menggunakan Unified Modelling Language (UML). Unified Modeling Language (UML) adalah bahasa grafis untuk memvisualisasikan, menentukan, membangun, dan mendokumentasikan artifak dari sistem perangkat lunak [6]. Salah satu diagram dalam UML adalah Use Case Diagram. Use case Diagram digunakan untuk menggambarkan proses sistem yang akan dikembangkan secara lebih jelas dan mudah dipahami. Use case diagram pada Sistem Penjadwalan Iklan Terintegrasi terdiri dari 7 (tujuh) use case dan 3 (tiga) aktor sistem seperti pada Gambar 1.

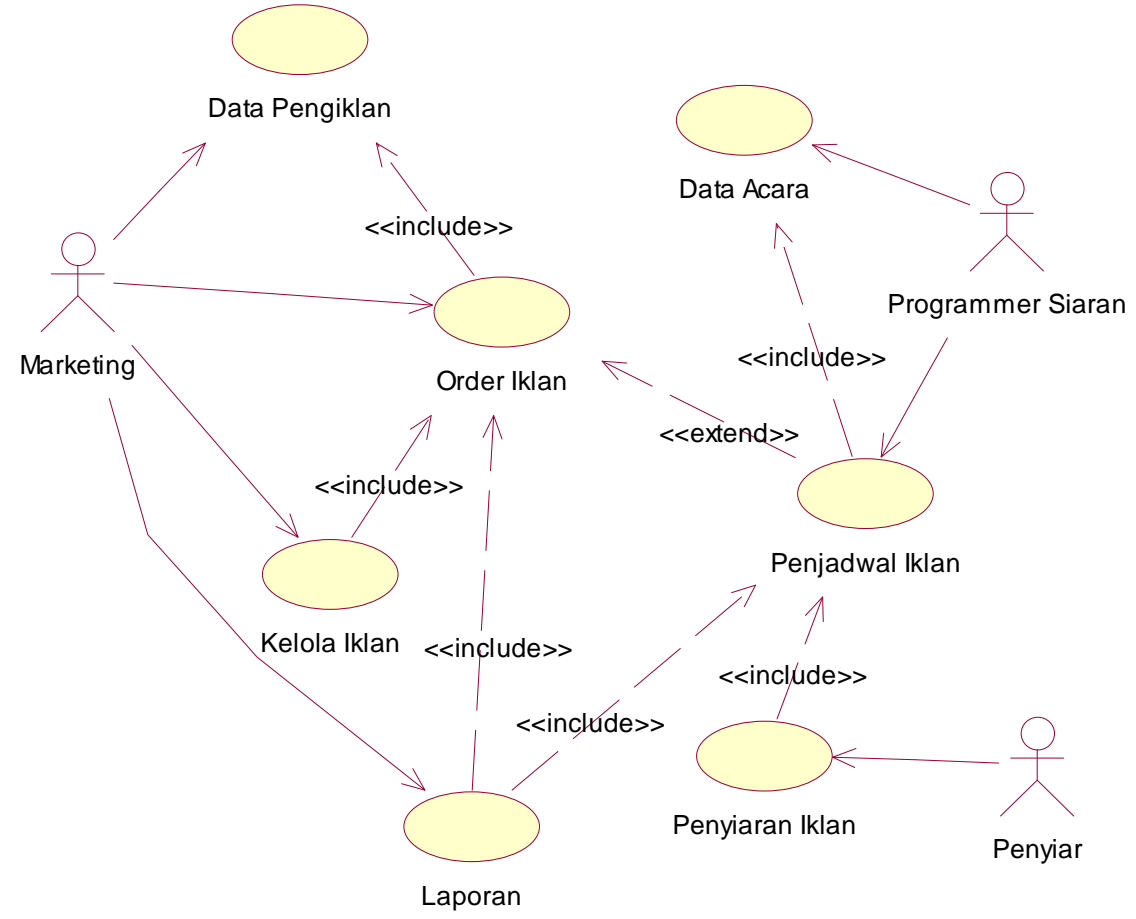

Gambar 1. Use Case Diagram Sistem Penjadwal Iklan Terintegrasi

Gambar 1 menunjukkan use case diagram yang digunakan dalam membangun Sistem Penjadwalan Iklan Terintegrasi. Dalam use case diagram tersebut, dapat dilihat 3 (tiga) aktor pengguna sistem yang memiliki hak akses yang berbeda. Adapun hak akses dari setiap pengguna sistem dapat dilihat pada Tabel 1 . 
Tabel 1. Daftar Hak Akses Pengguna Sistem

\begin{tabular}{lll}
\hline No & \multicolumn{1}{c}{ Jenis Pengguna } & \multicolumn{1}{c}{ Hak Akses } \\
\hline 1 & Marketing & 1. Mengelola data pengiklan (klien) \\
& & 2. Mengelola data iklan \\
& & 3. Mengelola data order iklan \\
& & 4. Serta melihat laporan \\
& \multirow{2}{*}{ Programmer Siaran } & 1. Mengelola data acara \\
3 & Penyiar & 2. Mengelola jadwal iklan \\
\hline
\end{tabular}

Langkah selanjutnya adalah merancang Class Diagram. Class diagram menggambarkan struktur sistem dari segi pendefinisian kelas-kelas yang akan dibuat untuk membangun sistem [6]. Class diagram memiliki atribut dan metode atau operasi. Atribut merupakan variabel-variabel yang dimiliki oleh suatu kelas, sedangkan metode atau operasi merupakan fungsi-fungsi yang dimiliki oleh kelas. Berdasarkan dari use case diagram tersebut, maka class diagram yang digunakan untuk membangun Sistem Penjadwalan Iklan Terintegrasi adalah seperti pada Gambar 2.

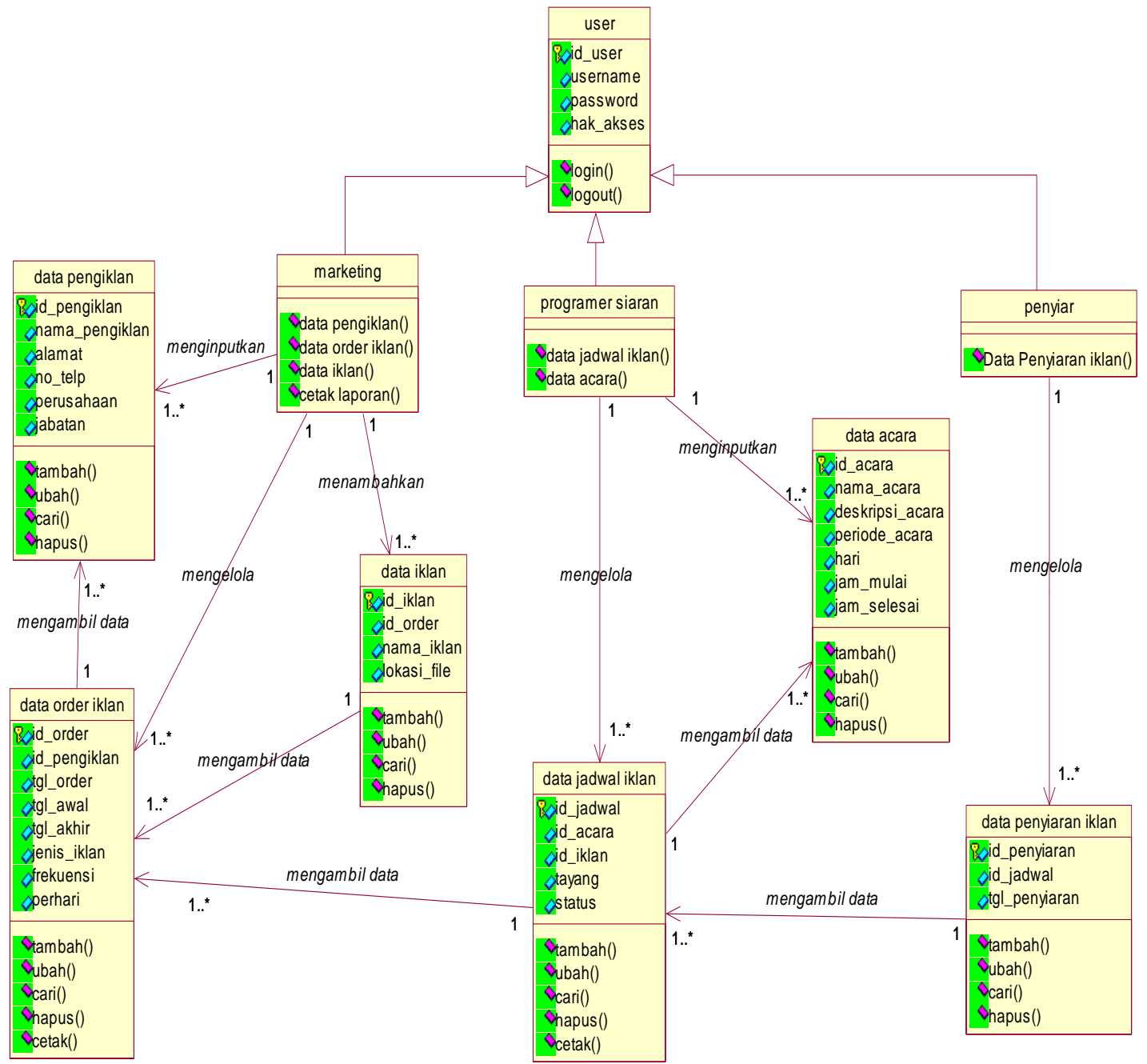

Gambar 2. Class Diagram Sistem Penjadwalan Iklan Terintegrasi

Dalam Gambar 2 terlihat sebanyak 10 (sepuluh) class, yang terdiri dari 6 (enam) class yang digunakan sebagai obyek transaksi data dan 3 (tiga) buah class aktor sistem serta 1 (satu) class inheritance yaitu class induk dari 3 class aktor sistem. 


\subsection{Perancangan Basis Data}

Database yang digunakan dalam Sistem Penjadwalan Iklan Terintegrasi pada Radio Suara Kudus adalah MySQL. Tabel yang digunakan dalam basis data penelitian ini adalah sebanyak 7 (tujuh) tabel seperti yang terlihat pada Gambar 3.

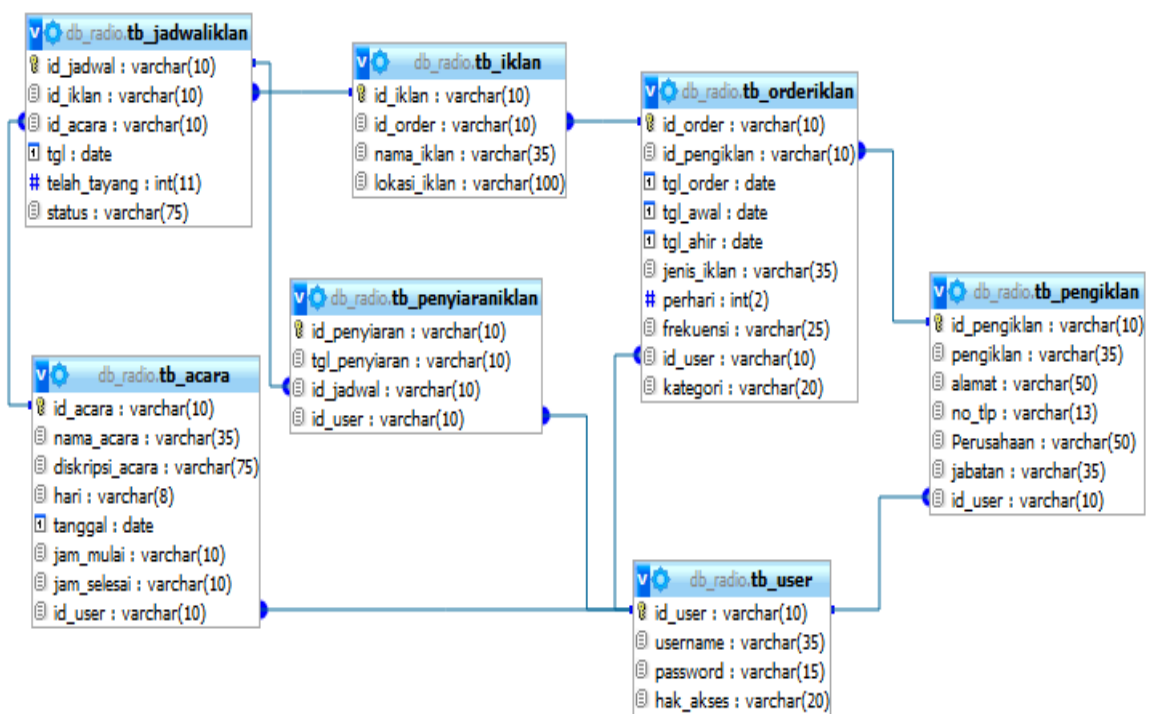

Gambar 3. Desain Relasi Tabel pada Database Sistem Penjadwalan Iklan Terintegrasi

\section{HASIL DAN PEMBAHASAN}

\subsection{Hasil}

Berikut ini adalah hasil dari pengembangan Sistem Penjadwalan Iklan Terintegrasi pada Radio Suara Kudus. Sistem dikembangkan menggunakan bahasa pemrograman Java Netbeans dan basis data MySQL. Adapun tampilan halaman utama dari sistem dapat dilihat pada Gambar 4.

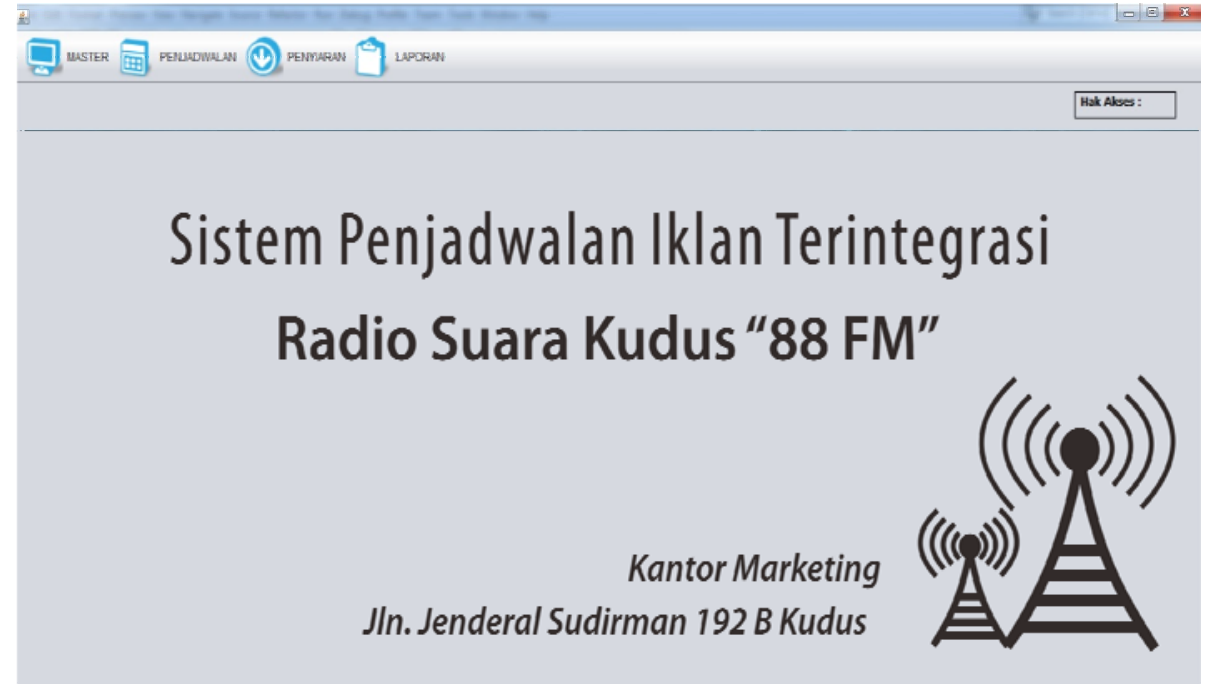

Gambar 4. Tampilan Halaman Utama Sistem Penjadwalan Iklan Terintegrasi 
Gambar 5 menunjukkan antarmuka untuk mengelola data order iklan dari klien yang digunakan oleh bagian marketing yang berisi order iklan yang di lakukan oleh pengiklan (klien), yang meliputi tanggal awal penayangan sampai tanggal akhir penayangan iklan, jenis iklan dan frekuensi iklan.

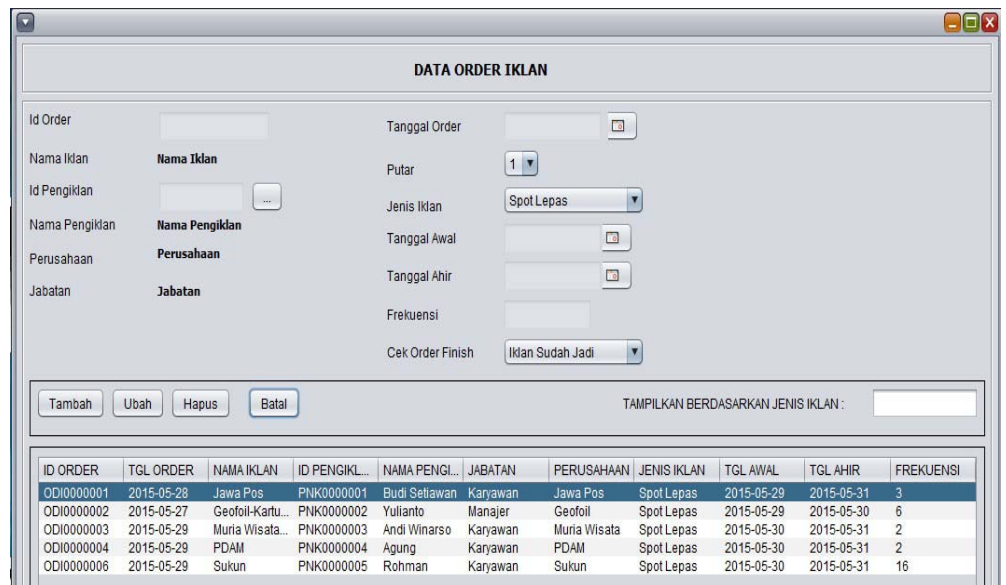

Gambar 5. Antarmuka Data Order Iklan (bagian marketing)

Sedangkan Gambar 6 menampilkan antarmuka data jadwal iklan yang digunakan oleh bagian programmer siaran untuk menjadwalkan iklan dalam suatu acara dengan terlebih dahulu menginputkan acara dan selanjutnya memasukkan iklan yang akan ditayangkan sesuai dengan order iklan.

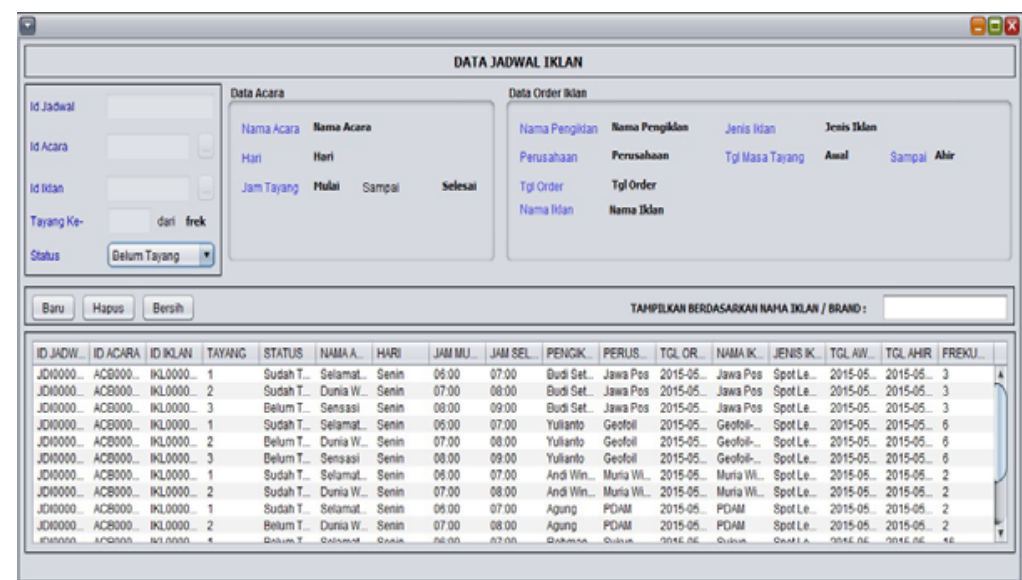

Gambar 6. Antarmuka Data Jadwal Iklan (bagian programmer siaran)

Gambar 7 menampilkan antarmuka data penyiaran iklan yang digunakan oleh penyiar pada saat siaran. Selain menayangkan iklan, antarmuka ini digunakan untuk melakukan pencatatan iklan yang ditayangkan sesuai dengan jadwal yang sudah ditentukan.

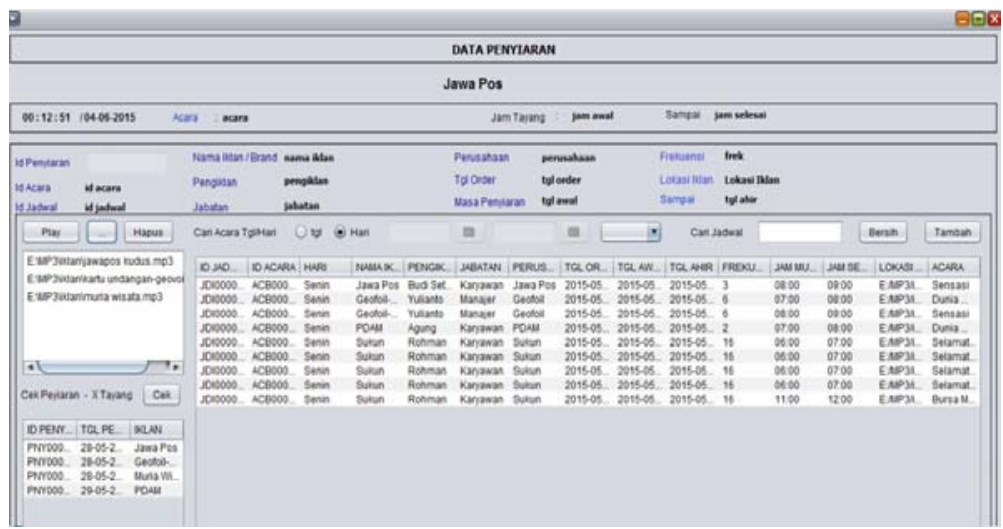

Gambar 7. Antarmuka Data Penyiaran Iklan (bagian penyiar) 
Pihak Radio Suara Kudus berkewajiban untuk memberikan informasi rekap siaran dalam bentuk laporan bukti siar kepada pengiklan (klien). Tugas ini dilakukan oleh bagian marketing melalui menu Laporan Penayangan Iklan seperti pada Gambar 8.

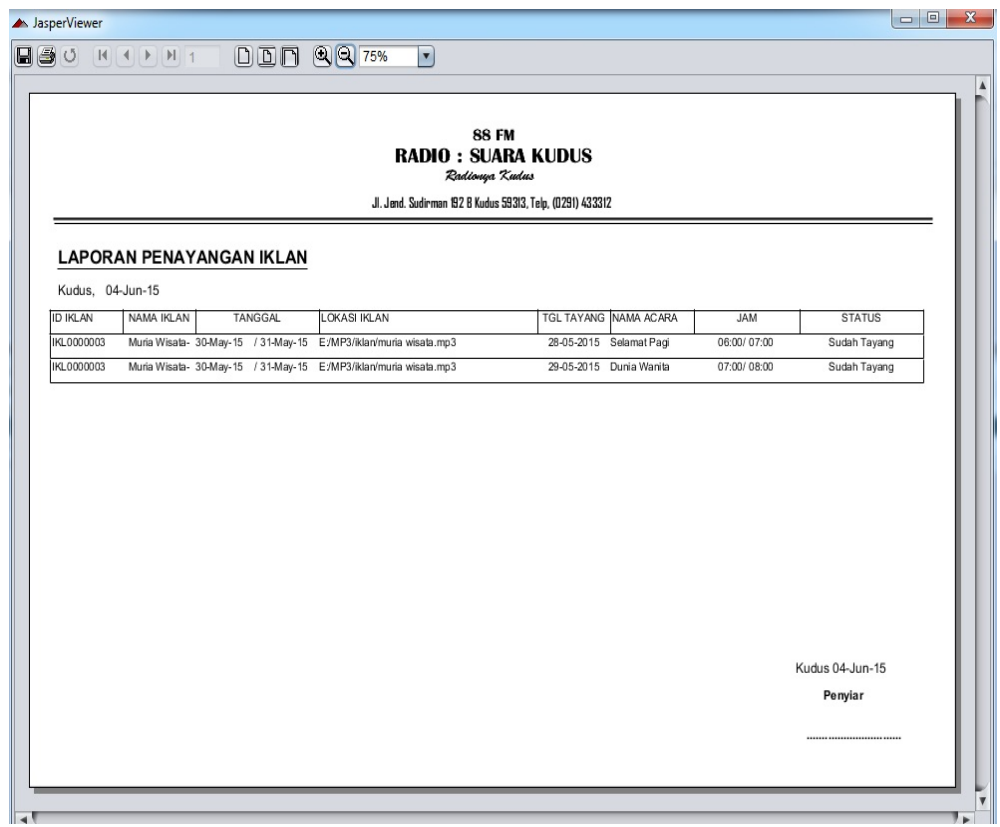

Gambar 8. Antarmuka Laporan Penayangan Iklan (bagian marketing)

\subsection{Pembahasan}

Untuk menguji kesesuaian aplikasi berdasarkan analisa dan perancangan, maka dilakukan pengujian fungsional dan non fungsional. Secara spesifik kriteria pengujian fungsional adalah sebagai berikut:

1) Mampu menampilkan dan mengelola data-data yang ada.

2) Perbandingan waktu antara sistem manual dengan sistem terkomputerisasi.

Sedangkan secara spesifik kriteria pengujian non fungsional adalah sebagai berikut:

1) Kenyamanan antarmuka,

2) Mudah digunakan (user friendly)

\section{KESIMPULAN}

\subsection{Kesimpulan}

1) Sistem Penjadwalan Iklan Terintegrasi merupakan sistem yang dapat membantu pengelolaan siaran iklan pada Radio Suara Kudus sehingga mempermudah dalam pencatatan order iklan dan penjadwalan iklan tersebut.

2) Dalam sistem ini, Penyiar dapat menayangkan iklan yang sudah dijadwalkan lebih cepat tanpa harus mencari file iklan didalam komputer, sehingga iklan dapat ditayangkan sesuai dengan jadwalnya.

3) Sistem dapat mencetak laporan bukti siar yang telah ditayangkan, sehingga akan meningkatkan efektivitas dan efisiensi dalam membuat laporan bukti siar.

\subsection{Saran}

Berikut ini adalah beberapa saran yang perlu diperhatikan untuk pengembangan lebih lanjut:

1) Sistem Informasi ini dapat dikembangkan menjadi berbasis web untuk memudahkan order iklan dan penjadwalan iklan.

2) Sistem Informasi ini dapat diterapkan untuk penjadwalan media lain, misalnya televisi.

3) Sistem Informasi ini dapat dikembangkan berbasis android sehingga mendukung mobilitas dari klien ketika akan melakukan order iklan. 


\section{UCAPAN TERIMA KASIH}

Terima kasih kami haturkan kepada Lembaga Pengabdian pada Masyarakat atas pembiayaan pada kegiatan ini melalui Anggaran Dana Pengabdian pada Masyarakat Universitas Muria Kudus Tahun 2016 serta pihak-pihak yang membantu sehingga kegiatan dapat diselesaikan dan dipublikasikan.

\section{DAFTAR PUSTAKA}

[1] Kasali, R, (1992), Manajemen Periklanan Konsep dan Aplikasinya di Indonesia, Jakarta: Pustaka Utama Grafiti.

[2] Baroto, T, (2002), Perencanaan dan Pengendalian Produksi, Jakarta: Ghalia Indonesia.

[3] Handoko, N, (2012), Sistem Informasi Pengolahan Data Iklan pada Stasiun Radio Pas FM Pati, Skripsi, Surakarta: Fakultas Teknik Universitas Surakarta.

[4] Annisa, (2014), Sistem Informasi Pemesanan Dan Penjadwalan Iklan Radio Karysma Fm Berbasis Web, Skripsi, Surakarta: Teknik Informatika FMIPA, Universitas Surakarta.

[5] Rismayani, Hasyrif, (2015), Implementasi Manajemen Sistem Informasi Siaran pada Radio Venus FM Makassar, Konferensi Nasional Sistem \& Informatika, Bali: STMIK STIKOM Bali.

[6] Sukamto, R. A, Shalahuddin, M, (2011), Model Pembelajaran Rekayasa Perangkat Lunak, Bandung: Modula. 